\title{
Oligopeptide permease in Borrelia burgdorferi: putative peptide-binding components encoded by both chromosomal and plasmid loci
}

\author{
James L. Bono, Kit Tilly, Brian Stevenson, Dan Hogan and Patricia Rosa
}

Laboratory of Microbial Structure and Function, Rocky Mountain Laboratories, National Institute of Allergy and infectious Diseases, 903 South Fourth Street, Hamilton, MT 59840, USA

\author{
Author for correspondence: Patricia Rosa. Tel: +1406363 9209. Fax: + 14063639204 \\ e-mail : parricia_rosa@nih.gov
}

\begin{abstract}
To elucidate the importance of oligopeptide permease for Borrelia burgdorferi, the agent of Lyme disease, a chromosomal locus in B. burgdorferi that encodes homologues of all five subunits of oligopeptide permease has been identified and characterized. B. burgdorferi has multiple copies of the gene encoding the peptide-binding component, OppA; three reside at the chromosomal locus and two are on plasmids. Northern analyses indicate that each oppA gene is independently transcribed, although the three chromosomal oppA genes are also expressed as bi- and tri-cistronic messages. Induction of one of the plasmid-encoded oppA genes was observed following an increase in temperature, which appears to be an important cue for adaptive responses in vivo. The deduced amino acid sequences suggest that all five borrelial OppA homologues are lipoproteins, but the protease-resistance of at least one of them in intact bacteria is inconsistent with outer-surface localization. Insertional inactivation of a plasmid-encoded oppA gene demonstrates that it is not essential for growth in culture.
\end{abstract}

Keywords: oligopeptide permease, $o p p A$, plasmids, Lyme disease, spirochaetes

\section{INTRODUCTION}

Borrelia burgdorferi, the spirochaetal agent of Lyme disease (Burgdorfer et al., 1982), is maintained in nature by an infectious cycle between tick vectors and small rodent hosts (Lane et al., 1991). Like many bacterial pathogens, $B$. burgdorferi must cope with an array of changing environmental conditions to successfully persist and proliferate in each location and to ensure subsequent transmission between hosts. To accomplish this, B. burgdorferi presumably must regulate gene expression in response to environmental cues. It is unknown how $B$. burgdorferi senses environmental changes and orchestrates the appropriate adaptive responses. In other bacteria, oligopeptide permeases can be involved in sensing pertinent environmental signals in the form of peptides, culminating in diverse responses such as expression of virulence determinants, sporulation, conjugation or competence (Clewell, 1993; Leonard et al., 1996; Perego et al., 1991; Rudner et al.,

The GenBank accession numbers for the opp nucleotide sequences reported in this paper are AF000365 (oppAV), AF000366 (chromosomal opp locus) and AF000948 (oppAIV).
1991). In addition to these signalling roles, the major role for most bacterial oligopeptide permeases is in nutrient uptake, by recycling cell wall and external peptides and transporting them into the cell, where they can be degraded into constituent amino acids for protein synthesis (Goodell \& Higgins, 1987; Payne \& Gilvarg, 1968).

We are interested in the potential role of oligopeptide permease in the transmission of $B$. burgdorferi between ticks and mammals. To initiate this investigation, we have identified genes that probably encode the $B$. burgdorferi oligopeptide permease, including homologues of the peptide-binding component OppA, the transmembrane components $\mathrm{OppB}$ and $\mathrm{OppC}$, and the associated ATPases OppD and OppF. A locus on the $B$. burgdorferi linear chromosome contains three oppA gene homologues, located adjacent to single copies of $o p p B, o p p C$, $o p p D$ and $o p p F$ gene homologues. Two plasmid loci, one on a $26 \mathrm{~kb}$ circular plasmid (cp26) and the other on a $54 \mathrm{~kb}$ linear plasmid (lp54), carry individual $o p p A$ gene homologues. We have characterized the transcripts from all five $o p p A$ genes and have demonstrated that a protein product from the $o p p A$ gene on cp 26 can be detected in B. burgdorferi lysates, 
but is not surface-exposed on intact bacteria. We have begun a genetic investigation of the biological roles of the individual $o p p A$ genes and oligopeptide permease in B. burgdorferi by inactivating the oppA gene on cp26.

\section{METHODS}

B. burgdorferi strains and growth conditions. B. burgdorferi B31 (ATCC 35210), the prototype strain for B. burgdorferi sensu stricto, was originally isolated from a tick collected on Shelter Island, NY (Burgdorfer et al., 1982). Wild-type B31 used in RNA and protein analyses was low passage and infectious. $\triangle o p p A \mathrm{IV}:: g y r B^{\mathrm{r}}$ mutant B31-82 was derived from high passage, non-infectious B31 by allelic exchange with recombinant plasmid pKK74, as described below. Cultures were grown in BSK-H medium (Sigma) supplemented with $6 \%(\mathrm{v} / \mathrm{v})$ rabbit serum at $34^{\circ} \mathrm{C}$ (Barbour, 1984), unless indicated otherwise. Single colonies in solid medium were obtained as described previously (Rosa et al., 1996).

Cloning and sequencing of the opp loci. While characterizing positive clones from a library of $B$. burgdorferi B31 DNA that had been screened with a guaA probe (Margolis et al., 1994), we identified an open reading frame homologous to OppA (probability $=5.6 \times 10^{-14}$ that the observed similarity to $S$. typhimurium OppA arose by chance), adjacent to guaB (Rosa et al., 1996). Sequence comparisons to protein sequence databases with this sequence (subsequently designated OppAIV) were performed using the BLAST network service (National Center for Biotechnology Information) and a BLASTP search (Altschul et al., 1990). A closely related sequence from B. coriaceae was also found; this sequence was a chromosomally encoded gene that was used as a PCR target sequence for the detection of B. coriaceae (Zingg \& LeFebvre, 1994).

An alignment of the B. burgdorferi oppAIV and B. coriaceae sequences permitted the identification of conserved amino acid residues, and a pair of degenerate oligonucleotides designed from these regions (Table 1, primers oppA.7 and oppA.4) was used in PCR amplification with total genomic B31 DNA. Although the amplification product migrated as a single band on an agarose gel, restriction digests indicated that it contained a mixture of DNA sequences. The undigested PCR fragments were cloned into the pCRII vector (Invitrogen) according to the manufacturer's instructions and restriction digests identified a clone with a novel insert. Sequence analysis indicated that it was homologous to, but distinct from, the oppAIVgene on cp26. Rehybridization of a Southern blot with a probe derived from this new oppA gene (subsequently designated $o p p A I I$ ) indicated that it hybridized most strongly with the chromosome in uncut DNA. The oppAII and oppAIV probes hybridized to the same set of restriction fragments in digested DNA (Fig. 1), but with different relative intensities (data not shown), with the oppAII probe binding strongly at high stringency to the same $6.5 \mathrm{~kb}$ EcoRI fragment as the $o p p D$ probe (described below, Fig. $1 \mathrm{~b}$ and data not shown).

A genomic library of B31 DNA constructed in Lambda Zap II (Stratagene) (Margolis et al., 1994) was screened with the oppAII gene probe and eight positive clones were characterized in detail. Portions of five different $o p p A$ genes were identified (these included oppAIV and oppAII). A combined strategy of PCR, Southern blotting and sequencing linked three oppA genes at a single chromosomal locus, upstream of $o p p B C D F$ homologues (described below) and located a single $o p p A$ gene on $\operatorname{lp} 54$, approximately $10 \mathrm{~kb} 3^{\prime}$ of the $\operatorname{osp} A B$ locus, in addition to oppAIV on cp26 (shown schematically in Fig. 2).

Degenerate primers for $o p p D$ and $o p p F$ (Table 1, primers oppD/F5', oppD3', oppF3') were designed to conserved residues based on an alignment of the deduced amino acid sequences of ATP-binding proteins from various oligopeptide transport systems (Hyde et al., 1990; Mimura et al., 1991) and used in PCR with B. burgdorferi DNA. Amplification products were cloned into the pCRII vector (Invitrogen) and sequence analysis (see below) confirmed that the cloned segments of borrelial DNA were derived from $o p p D$ and $o p p F$ homologues. PCR fragments (Table 1, primers oppD/F5'-oppD3' and oppD/F5'-oppF3') were used as probes in Southern blots to map the borrelial $o p p D$ and $o p p F$ genes to a chromosomal locus that is linked to the $o p p A$ homologues (Fig. $1 \mathrm{~b}$ and data not shown), and to screen the genomic library of B31 DNA. Sequence analysis of the genomic clones identified borrelial $o p p B$ and $o p p C$ homologues immediately upstream of $o p p D$ and $o p p F$ genes (see Fig. 2).

The nucleotide sequences of all opp genes were obtained from both strands using either Sequenase 2.0 (US Biochemicals) or a 373A automated DNA sequencer (Applied Biosystems). The nucleotide sequences of $B$. burgdorferi opp genes and flanking DNA on $\mathrm{cp} 26(3.5 \mathrm{~kb}), \operatorname{lp} 54(2.0 \mathrm{~kb})$ and the chromosome $(12.2 \mathrm{~kb})$ have been deposited in GenBank (accession numbers AF000948, AF000365 and AF000366, respectively). Our sequence for the $o p p$ loci differs from unedited genomic sequence determined by The Institute for Genomic Research and available at http://www.tigr.org as follows: four nucleotide substitutions in oppAI resulting in four amino acid changes; four nucleotide substitutions in oppAII resulting in two amino acid changes; two nucleotide substitutions in oppAIII resulting in one amino acid change ; one nucleotide substitution in oppC resulting in an amino acid change and one nucleotide insertion in $o p p C$ resulting in an altered reading frame for 76 amino acids and truncation of 87 amino acids; no nucleotide differences in $o p p D$ and $o p p F$; one nucleotide difference in $o p p A I V$ that did not alter the amino acid sequence; and two nucleotide differences in oppAV that resulted in two amino acid changes. There were also four nucleotide differences (one substitution, three insertion/deletions) in the oppAII-oppAIII intergenic region.

Southern blot analysis of the opp loci. Total genomic DNA was isolated from $B$. burgdorferi as previously described (Rosa \& Schwan, 1989). Total plasmid DNA, including both linear and circular molecules, was isolated from B. burgdorferi with Qiagen columns following the manufacturer's instructions. Southern blot analyses (Southern, 1975) were performed after DNA was separated on a $0.8 \%(\mathrm{w} / \mathrm{v})$ agarose gel by field inversion electrophoresis for $24 \mathrm{~h}$ at $7 \mathrm{~V} \mathrm{~cm}^{-1}$ with program 3 of a PPI-200 programmable power inverter (MJ Research). DNA was transferred to Biotrans nylon membranes (ICN), prehybridized and hybridized with radioactive probes in $6 \times$ SSC (where $20 \times$ SSC is $3 \mathrm{M}$ sodium chloride, $0.3 \mathrm{M}$ sodium citrate), $0.1 \%(\mathrm{w} / \mathrm{v})$ SDS, $0.5 \%(\mathrm{w} / \mathrm{v})$ non-fat dry milk, $1 \mathrm{mM}$ sodium pyrophosphate at $55^{\circ} \mathrm{C}$ (high stringency) or $45^{\circ} \mathrm{C}$ (low stringency) in rotating bottles in a hybridization oven (Bellco). Probe fragments were generated by PCR amplification and radiolabelled with $\left[\alpha^{32} \mathrm{P}\right] \mathrm{dATP}$ (Du Pont) by random priming (Life Technologies). Blots were washed in $0 \cdot 2 \times \operatorname{SSC}, 0.1 \%(\mathrm{w} / \mathrm{v}) \mathrm{SDS}$ at $55^{\circ} \mathrm{C}$ (high stringency) or $2 \times$ SSC, $0.1 \%(\mathrm{w} / \mathrm{v})$ SDS at room temperature (low stringency) and visualized by autoradiography.

Northern blot analysis of the opp genes. Total borrelial RNA was extracted from exponential-phase cultures using the 
Table 1. Oligonucleotide primers used in this study

\begin{tabular}{|c|c|c|c|}
\hline Our designation & Sequence $\left(5^{\prime} \rightarrow 3^{\prime}\right)$ & Gene & $\begin{array}{c}\text { Use for } \\
\text { oligonucleotides }\end{array}$ \\
\hline $\mathrm{U} 157 \mathrm{~F}+H p a \mathrm{I}$ & ACCGTTAACTTTTAACATTATATAGTAT & $5^{\prime}$ gyrB & Mutant construction \\
\hline $1905 \mathrm{R}+B c l \mathrm{I}$ & ACCTTGATCATTACACATCAAGATTAATTAC & $3^{\prime}$ gyrB & Mutant construction \\
\hline gb.10 & ATTACCTAGTGAGGTTAGTT & $5^{\prime}$ gua & Probe \\
\hline gb. 32 & TAAATCAGATATTGTTGCTG & $3^{\prime}$ guaB & Probe \\
\hline gb.19 & GAAAGATGCTTAAGAACGTC & $5^{\prime}$ oppAIV & Probe \\
\hline $\mathrm{gb} .29$ & CAGGGATTGTAAGCCAAATGT & $3^{\prime}$ oppAIV & Probe \\
\hline oppB.1 & GAGGAGCAATGTTGCCTGTA & $5^{\prime}$ oppBC & Probe \\
\hline oppD.2 & CTCCTGAAAATTGATGTGGG & $3^{\prime}$ oppBC & Probe \\
\hline gspI.1 & ATAGTTGTTAGTGGCGCATAC & $S^{\prime}$ oppAI & Specific probe \\
\hline oppA.50 & ATTGAATGCTATGTATGCCATTCCG & $3^{\prime}$ oppAI & Specific probe \\
\hline gspII.1 & AATGAAGTAGAATTAGAAGAG & $5^{\prime}$ oppAII & Specific probe \\
\hline gspII.2 & GTTGTCAAGTGGTTTGATGTG & $3^{\prime}$ oppAII & Specific probe \\
\hline gspIII.1 & AACGAACGTTATTATAATGCA & $5^{\prime}$ oppAIII & Specific probe \\
\hline gspIII. 2 & ATAAATTGCATTACTTTTGTGTTGG & $3^{\prime}$ oppAIII & Specific probe \\
\hline gspIV.1 & GATGTTGTTCTTGACAGTATT & $5^{\prime}$ oppAIV & Specific probe \\
\hline gspIV.2 & AAGCGGTTTTACTTTCATGTTC & 3' oppAIV & Specific probe \\
\hline gspV.1 & AATGAAAAATTCTATGATGCT & $S^{\prime}$ oppAV & Specific probe \\
\hline gspV.2 & AGGTTTAACATTTGTGTTTAGTG & $3^{\prime}$ oppAV & Specific probe \\
\hline oppA. $7^{*}$ & CAAACHTTYATHCCWGTWCC & $5^{\prime}$ oppA & Degenerate primer \\
\hline oppA.4* & KTCCAYTTRTCRTKYCTRAA & $3^{\prime}$ oppA & Degenerate primer \\
\hline oppD/F $5^{*}$ & GTWGGWGARWSHGGWWSHGG & $5^{\prime}$ oppDF & Degenerate primer \\
\hline oppD $3^{\prime *}$ & ARWGCWGTWGTWGGYTCRTC & $3^{\prime}$ oppD & Degenerate primer \\
\hline oppF $3^{\prime *}$ & WAYWGAWAVRTCWARWGC & $3^{\prime}$ oppF & Degenerate primer \\
\hline
\end{tabular}

*IUB Group Codes identifying base redundancies in the degenerate primers: $R=A+G, Y=C+T, M=A+C, K=G+T, S=G+C$, $\mathrm{W}=\mathrm{A}+\mathrm{T}, \mathrm{H}=\mathrm{A}+\mathrm{T}+\mathrm{C}, \mathrm{D}=\mathrm{G}+\mathrm{T}+\mathrm{A}, \mathrm{N}=\mathrm{A}+\mathrm{C}+\mathrm{G}+\mathrm{T}, \mathrm{V}=\mathrm{G}+\mathrm{A}+\mathrm{C}$.

RNAgents Total RNA isolation system (Promega) or the Ultraspec RNA isolation system (Biotecx) according to the manufacturer's instructions. For temperature shift experiments, borreliae were grown at $23^{\circ} \mathrm{C}$ to mid-exponential phase, diluted $1: 100$ in fresh medium, and grown to midexponential phase at $35^{\circ} \mathrm{C}$. RNA was denatured with glyoxal and dimethyl sulfoxide and electrophoresed in a $1 \%(\mathrm{w} / \mathrm{v})$ agarose gel in $10 \mathrm{mM}$ sodium phosphate buffer, $\mathrm{pH} 7 \cdot 0$ (Sambrook et al., 1989). The RNA was transferred to nylon membranes (Micron Separations), cross-linked with ultraviolet light and air dried. Prehybridization and hybridization were at $55{ }^{\circ} \mathrm{C}$ in $1 \%(\mathrm{w} / \mathrm{v}$ ) BSA, $7 \%(\mathrm{w} / \mathrm{v}$ ) SDS, $0.5 \mathrm{M}$ sodium phosphate, $\mathrm{pH} 7 \cdot 0$, and $1 \mathrm{mM}$ EDTA in rotating bottles in a hybridization oven (Bellco). Probe fragments were generated by PCR amplification and radiolabelled with $\left[\alpha{ }^{32} \mathrm{P}\right] \mathrm{dATP}(\mathrm{Du}$ Pont) by random priming (Life Technologies). Membranes were washed at $55^{\circ} \mathrm{C}$ in $0.2 \times \mathrm{SSC}, 0.1 \%(\mathrm{w} / \mathrm{v}) \mathrm{SDS}$.

Construction of oppAIV mutant. The plasmid construct used to inactivate the oppAIV gene was generated in several sequential cloning steps. First, the $g y r B^{r}$ gene from the coumermycin-resistant B31 variant NGR (Rosa et al., 1996) was amplified using primers U157F HpaI and 1905R BclI (Table 1). The amplification product was ligated into the pCRII vector and transformed into Escherichia coli strain $I N V \alpha \mathrm{F}^{\prime}$ as recommended by the manufacturer (Invitrogen), and then moved into E. coli strain GM119 (Arraj \& Marinus, 1983), which lacks both dam and $d c m$ methylases. Plasmid DNA from the GM119 background was digested with $H p a I$ and $B c l I$, and the $g y r B^{r}$-containing fragment purified from an agarose gel using NA45 membrane (Schleicher and Schuell).
This fragment was ligated with $\mathrm{Hpal} /$ Bglll-digested pDH63 (Rosa et al., 1996), a genomic clone isolated from the $B$. burgdorferi B31 DNA library whose $3.5 \mathrm{~kb}$ insert is derived from cp26 and spans the oppAIV and guaB genes. The resultant plasmid, pKK73, contains a gyrB insertion and corresponding deletion of oppAIV, between the HpaI site located approximately $400 \mathrm{bp}$ within the gene to the $B g l$ II site $30 \mathrm{bp}$ beyond the $3^{\prime}$ end of the gene (Fig. 2). pKK73 contains only a small segment of oppAIV upstream of the $g y r B^{\mathrm{r}}$ insertion, so those sequences were replaced with the $2 \mathrm{~kb}$ PstI-HpaI fragment from pDH62, another cp26-derived genomic clone whose insert extends approximately $1.5 \mathrm{~kb} 5^{\prime}$ of oppAIV, to create pKK74. This construct has approximately $2 \mathrm{~kb}$ and $1.4 \mathrm{~kb}$ of cp26 sequence flanking gyr $B^{\mathrm{r}}$ on the $5^{\prime}$ and $3^{\prime}$ ends, respectively. pKK74 was digested with PvuI to inactivate the bla gene (which removes the ability of this plasmid to confer ampicillin resistance) and the large fragment was purified from an agarose gel using a Unidirectional Electroelutor (model UEA, IBI). This DNA was used to transform B. burgdorferi $\mathrm{B} 31$ by electroporation as previously described (Rosa et al., 1996; Samuels et al., 1994).

Coumermycin-resistant colonies were screened by PCR to identify transformants with targeted insertion of $g y r B^{\mathrm{r}}$ in oppAIV. The structure of mutant oppAIV on cp26 was confirmed by PCR with five different primer pairs between gyrB and cp26 flanking sequences and by Southern blot analysis of plasmid DNA from wild-type and oppAIV mutant borreliae with both oppAIV and $g y r B$ probes. The results were consistent only with the deletion-insertion structure of the anticipated oppAIV mutant ( $\triangle$ oppAIV ::gyr $\left.B^{\mathrm{r}} \mathrm{cp} 26\right)$. Although 
plasmids can be present at multiple copies per spirochaete (Kitten \& Barbour, 1992), we have found no examples of transformants in which the selectable marker was present in only some copies of the plasmid (Rosa et al., 1996; Tilly et al., 1997).

PCR conditions for cloning, generating probes and analysing recombinants. Oligonucleotides used as PCR primers for cloning and generating probes are described in Table 1. Coumermycin-resistant colonies were screened for the presence of the gyr $B^{r}$ gene within oppAIV by PCR in a 9600 DNA Thermal Cycler (Perkin Elmer/Applied Biosystems) as previously described (Rosa et al., 1996). PCR conditions for cloning, generating probes and analysing recombinants were 25 cycles of $94^{\circ} \mathrm{C}$ for $1 \mathrm{~min}, 50^{\circ} \mathrm{C}$ for $0.5 \mathrm{~min}$ and $70{ }^{\circ} \mathrm{C}$ for 3 min. Probe fragments were amplified through two rounds of PCR with a $1: 100$ dilution of the first reaction to minimize carryover of the template genomic DNA in the final PCR product. PCR conditions with degenerate primers were 30 cycles of $94^{\circ} \mathrm{C}$ for $1 \mathrm{~min}, 50^{\circ} \mathrm{C}$ for $2.0 \mathrm{~min}$ and $65^{\circ} \mathrm{C}$ for 2 min, using $1 \mu \mathrm{g}(150 \mathrm{pM})$ primer per $100 \mu \mathrm{l}$ reaction mixture.

SDSPAGE and Western blotting of proteins. B. burgdorferi extracts were prepared from equal culture volumes by pelleting the bacteria, washing twice in PBS, and resuspending in sample buffer (Sambrook et al., 1989). After boiling for 5 min, lysates were separated by electrophoresis through $12.5 \%$ $(\mathrm{w} / \mathrm{v})$ or $10 \%(\mathrm{w} / \mathrm{v})$ polyacrylamide gels (King \& Swanson, 1978) in a Mini-Protean II cell (Bio-Rad). Proteins were blotted to nitrocellulose (Life Technologies), probed with polyclonal serum (anti-OppAIV, see below, or anti-OspC, Schwan et al., 1993) or hybridoma supernatant (anti-OspB monoclonal H4610, Rosa et al., 1992), and antibody-bound proteins were detected as previously described (Tilly et al., 1997) using enhanced chemiluminescence reagents as recommended by the manufacturer (Amersham). OppAIV was cloned, expressed and purified as a fusion protein with maltose-binding protein (MBP), according to the manufacturer's instructions (New England Biolabs). Polyclonal rabbit antiserum was raised against the purified recombinant OppAIV-MBP fusion protein. OppAI-V were individually cloned and expressed in the pCRII vector (Invitrogen). The proteinase $\mathrm{K}$ sensitivity of borrelial proteins on viable spirochaetes was assayed by a modification of the protocol described by Barbour et al. (1984). Briefly, spirochaetes were pelleted and washed once in PBS- $\mathrm{Mg}^{2+}$, resuspended at a concentration of $2 \times 10^{9}$ cells $\mathrm{ml}^{-1}$ and incubated at room temperature for $40 \mathrm{~min}$ with varying amounts of proteinase $\mathrm{K}$ $\left(0,0 \cdot 04,0 \cdot 2\right.$ and $\left.1 \mathrm{mg} \mathrm{ml}^{-1}\right)$. After inhibiting proteinase $\mathrm{K}$ with PMSF, bacteria were pelleted, washed twice in PBS- $\mathrm{Mg}^{2+}$, resuspended in sample buffer and boiled for $5 \mathrm{~min}$ before analysis by SDS-PAGE and immunoblotting as described above.

\section{RESULTS}

\section{Plasmid and chromosomal copies of oppA}

We initially identified a homologue of oppA on cp26 of $B$. burgdorferi, located approximately $300 \mathrm{bp}$ downstream of the guaAB locus and in the opposite orientation (Rosa et al., 1996). No open reading frames homologous to other components of oligopeptide permease were located in either the upstream $(1.6 \mathrm{~kb})$ or downstream $(3 \cdot 1 \mathrm{~kb})$ flanking regions. Additional copies of $o p p A$ were subsequently identified elsewhere in the genome by a Southern blot of total undigested borrelial DNA hybridized at low stringency with a probe derived (a)

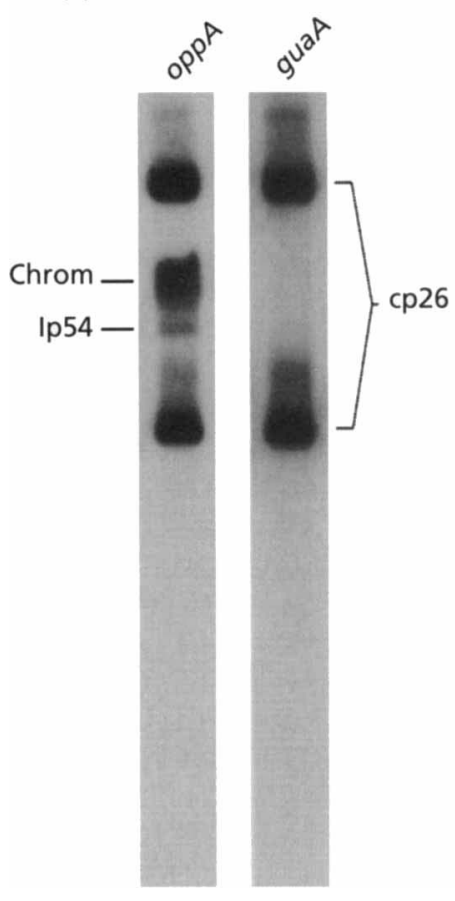

(b)

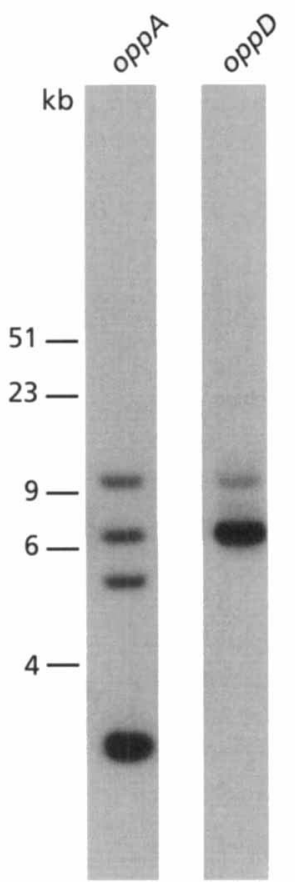

Fig. 1. Southern blot analysis of $B$. burgdorferi B31 opp and guaA genes. Blots containing uncut (a) and EcoRI-digested (b) DNA from strain B31 were sequentially hybridized to guaA and oppAIV probes (a), or oppAIV and oppD probes (b). Hybridizations were done at $45^{\circ} \mathrm{C}$ and blots were washed at low stringency. Radioactivity on blots was allowed to decay to undetectable levels between hybridizations. The mobilities of size standards (in kb) are indicated. Chrom, chromosome.

from the cp26 oppA gene (Fig. 1a). In addition to the supercoiled and nicked forms of cp26 (indicated by hybridization with a guaA probe), this probe also hybridized to the sheared chromosomal DNA and to a $54 \mathrm{~kb}$ linear plasmid (lp54, Fig. 1a). Southern blots of total genomic DNA digested with restriction enzymes that did not cut within the cp26 oppA gene contained multiple fragments that hybridized to the oppA probe at low stringency. For example, the oppA probe hybridized with four EcoRI fragments (Fig. 1b); washing this blot at increased stringency led to greatly reduced hybridization with the three larger fragments (not shown). These results suggested the presence of additional $o p p A$ genes on the chromosome and $\operatorname{lp} 54$.

\section{Chromosomal locus encoding all five components of oligopeptide permease}

Since many bacteria have the genes encoding all five components of oligopeptide permease at a chromosomal locus, we looked for a similar organization in $B$. burgdorferi. Alignments of the amino acid sequences of the ATPase subunits, OppD and OppF, from a diverse group of bacteria have identified several highly conserved regions (Higgins et al., 1986; Hyde et al., 1990; Mimura et al., 1991). Degenerate oligonucleotides from these regions (Table 1) were used in PCR with $B$. 

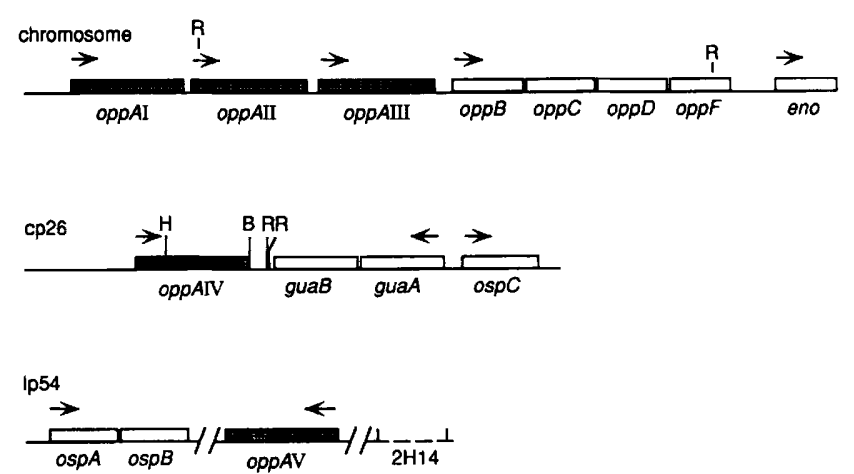

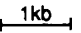

Fig. 2. Schematic representation of the $B$. burgdorferi opp loci. Arrows indicate the direction of transcription. Bgfll, Hpal and EcoRI sites are indicated by the letters $B, H$ and $R$, respectively. The ospA/B (Bergstrom et al., 1989) and $2 \mathrm{H} 14$ (Rosa \& Schwan, 1989) loci are located approximately $10 \mathrm{~kb} 5^{\prime}$ and $6 \mathrm{~kb} 3^{\prime}$, respectively, of oppAV on Ip54.

burgdorferi DNA. Sequence analyses of PCR products of the anticipated sizes confirmed their identities as portions of $o p p D$ and $o p p F$. An amplification product spanning $o p p D$ and $o p p F$ was also obtained, indicating that these genes are adjacent in B. burgdorferi, as is true in other bacteria. The Southern blot of EcoRI-digested DNA hybridized with the $o p p A$ probe was rehybridized with an $O p p D$ probe, after the $o p p A$ signal had decayed (Fig. 1b); $6.5 \mathrm{~kb}$ and $9 \mathrm{~kb}$ EcoRI fragments were recognized by both probes. Similar co-hybridization of $o p p A$ and $o p p D$ probes was seen with borrelial DNA digested with several other enzymes (not shown). The oppD probe only hybridized to chromosomal DNA in undigested DNA (not shown), suggesting the presence of a chromosomal locus in B. burgdorferi with homologues of the $o p p A$, $o p p D$ and $o p p F$ genes.

To more fully characterize this chromosomal locus, $o p p A$ and $o p p D$ probes were used to screen a $B$. burgdorferi genomic library (described in Methods). Sequence analysis of a number of positive clones defined a $10 \mathrm{~kb}$ chromosomal locus that contained seven open reading frames (Fig. 2), whose deduced amino acid sequences included homologues of three substratebinding OppA proteins, the integral membrane proteins $O p p B$ and OppC, and the ATPases OppD and OppF. In addition to the previously characterized $o p p A$ gene on сp26, an $о p p A$ homologue unlinked to other permease components was identified on lp54 (Fig. 2). We designated the chromosomal $o p p A$ homologues as $o p p A \mathrm{I}$, II and III, the cp26 homologue as oppAIV and the lp54 homologue as oppAV (Fig. 2). An open reading frame encoding a homologue of enolase resides approximately $1 \mathrm{~kb}$ downstream of $o p p F$; there are no other readily identifiable sequences within approximately $1 \mathrm{~kb}$ upstream of the chromosomal locus or $0.6 \mathrm{~kb}$ on either side of $o p p A \mathrm{~V}$ on $\operatorname{lp} 54$.

The three loci shown diagrammatically in Fig. 2 account for all the EcoRI fragments that hybridized to the oppA probe (Fig. 1b); the smallest fragment is from cp26, the $6.5 \mathrm{~kb}$ fragment is part of the chromosomal locus (oppAII-III), and the remaining two fragments of approximately 5 and $9 \mathrm{~kb}$ are from lp 54 or the remainder of the chromosomal locus (oppAI-II). Although the $o p p D$ probe also weakly hybridized to a $9 \mathrm{~kb}$ fragment (Fig. 1b), the location of EcoRI sites in the chromosomal locus indicates that this fragment is not derived from the $o p p D$ gene at this site; a related gene may be further upstream of $o p p A \mathrm{I}$. Alternatively, the $9 \mathrm{~kb} o p p D$ and $o p p A$ fragments could be unrelated, co-migrating fragments. From this analysis (and digests with other restriction enzymes) there is no indication of additional oppA genes in the B. burgdorferi genome.

\section{Characteristic sequence motifs and predicted structures}

The linkage of three oppA homologues to homologues of $o p p B C D F$ at the chromosomal locus strongly suggests that they collectively encode a borrelial oligopeptide permease. In addition to overall sequence similarity, the deduced borrelial Opp proteins have predicted structural features and sequence motifs that are consistent with their proposed transport functions and inclusion in the ABC (ATP-binding cassette) transporter family (Higgins, 1992; Higgins et al., 1986).

Like many nucleotide-binding proteins, the B. burgdorferi OppD and $\mathrm{OppF}$ homologues contain two short sequence motifs known as Walker boxes that are proposed to contribute to the nucleotide-binding fold in the predicted structure (Walker et al., 1982). ATPbinding components of $\mathrm{ABC}$ transporters (such as $\mathrm{OppD}$ and $\mathrm{OppF}$ ) also exhibit a highly conserved sequence known as the loop 3 region, which is thought to interact directly with the transmembrane components (OppB and $\mathrm{OppC}$, and couple ATP hydrolysis to the transport process (Higgins, 1992; Hyde et al., 1990; Mimura et al., 1991); this region is also found in the B. burgdorferi OppD and OppF homologues.

Hydropathy analyses of the deduced borrelial OppB and OppC homologues indicate five to six potential membrane-spanning domains (not shown), consistent with the proposed structures of these integral membrane components in other bacteria (Dassa \& Hofnung, 1985; Higgins, 1992; Pearce et al., 1992). A unique feature of the B. burgdorferi OppC sequence relative to OppC of other bacteria is an additional 53 residues within the predicted periplasmic loop between the first and second membrane-spanning regions.

The solute-binding components confer high-affinity substrate specificity upon the $\mathrm{ABC}$ transport systems with which they interact. Tam \& Saier (1993) have defined eight families or clusters of bacterial solutebinding proteins based on amino acid sequence similarity. The deduced borrelial OppA sequences are most similar to members of cluster 5 , which includes the peptide- and nickel-binding proteins, and each OppA homologue contains a good match to the consensus 


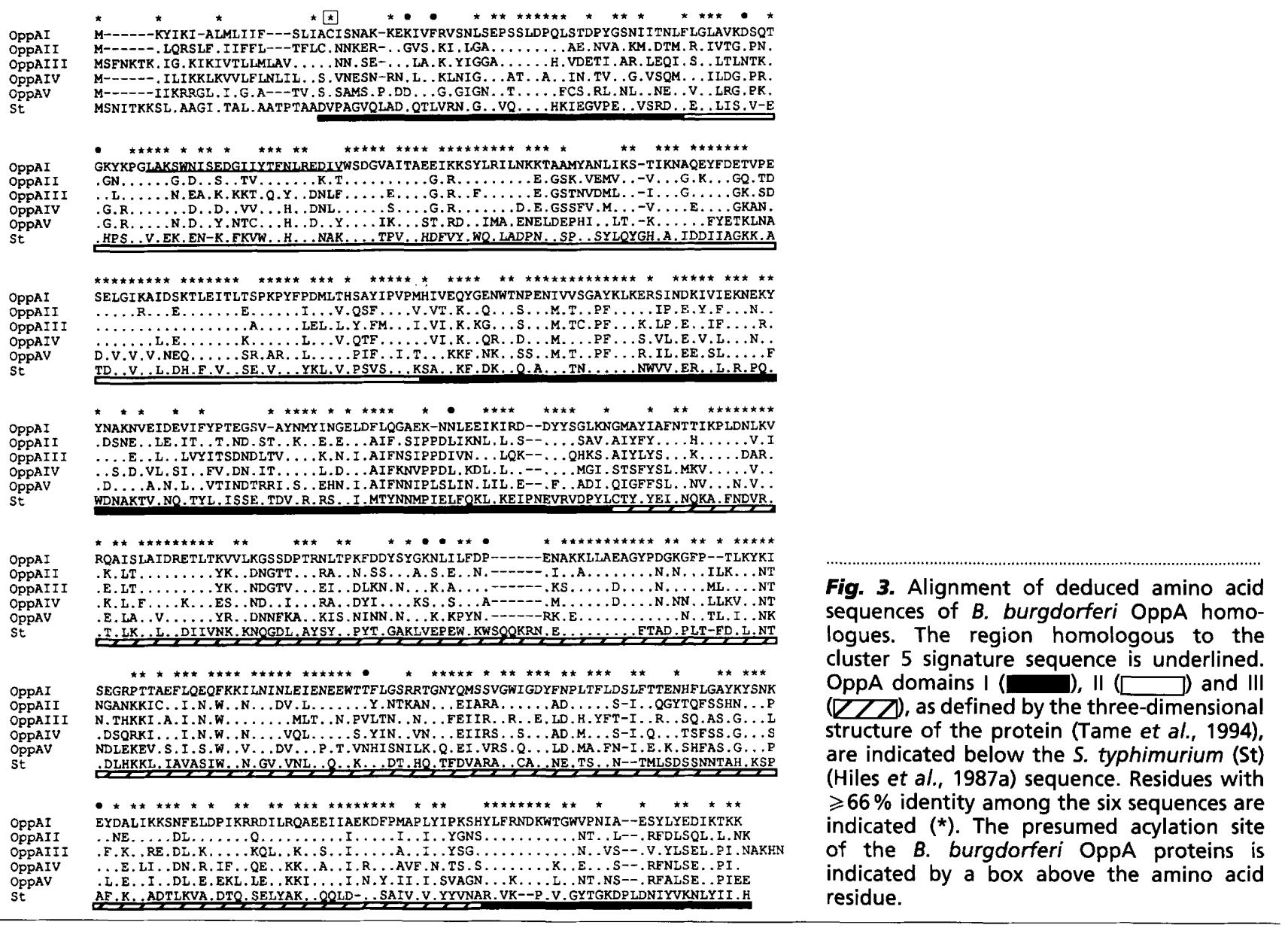

Table 2. Identity of the deduced amino acid sequences of OppA homologues

Comparisons were performed of OppA homologues from Borrelia burgdorferi (Bb), Bacillus subtilis

(Bs) (Perego et al., 1991), Salmonella typhimurium (St) (Hiles et al., 1987a), and Enterococcus

faecalis TraC (Ef) (Tanimoto et al., 1993) without leader sequences, using the CLUSTAL v program

with the following alignment parameters: fixed gap penalty, 10; floating gap penalty, 10; protein weight matrix, PAM250. Values indicate percentage of identical residues.

\begin{tabular}{|lrrrrrrrr|}
\hline Gene & Bb I & Bb II & Bb III & Bb IV & Bb V & Bs & St & Ef \\
\hline Bb I & 100 & & & & & & & \\
Bb II & 56 & 100 & & & & & & \\
Bb III & 52 & 60 & 100 & & & & & \\
Bb IV & 54 & 64 & 59 & 100 & & & & \\
Bb V & 44 & 51 & 50 & 52 & 100 & & & \\
Bs & 22 & 27 & 26 & 29 & 24 & 100 & & \\
St & 26 & 27 & 28 & 28 & 25 & 29 & 100 & \\
Ef & 23 & 22 & 23 & 23 & 22 & 26 & 22 & 100 \\
\hline
\end{tabular}

signature sequence for cluster 5 solute-binding proteins (underlined in Fig. 3).

\section{OppA sequence comparisons}

B. burgdorferi OppA homologues share approximately $25 \%$ identity with OppA proteins from Bacillus subtilis (Perego et al., 1991; Rudner et al., 1991) and Salmonella typhimurium (Hiles et al., 1987a), similar to the degree of sequence identity shared between the OppA proteins of the latter two, and with TraC from Enterococcus faecalis, a plasmid-encoded OppA homologue that is a receptor for a peptide pheromone (Tanimoto et al., 1993) (Table 2). Relatedness among the five B. burgdorferi OppA homologues ranges from $44 \%$ to $64 \%$ identity and does not correlate with genomic location 
(Table 2). Hydropathy plots of all five deduced $B$. burgdorferi OppA proteins were very similar to each other and to those of other bacterial OppAs (not shown).

Aligning the deduced amino acid sequences of $B$. burgdorferi OppAI-V with OppA from S. typhimurium indicated conserved residues throughout (Fig. 3). Although all of the OppA proteins contain hydrophobic leader sequences, and each of the deduced B. burgdorfer $i$ OppA proteins contains a consensus signal peptidase II cleavage/lipidation site (LXYC or LXYZC) (Wu \& Tokunaga, 1986), the amino-terminal regions of the proteins are the most divergent. The crystal structure of S. typhimurium OppA defines three domains (Tame et al., 1994); the deduced B. burgdorferi OppA gene products are homologous to $S$. typhimurium OppA in all three domains (Fig. 3).

\section{Expression of oppA genes}

The organization of the chromosomal $o p p$ genes suggests that $o p p A$ I, II and III could be individually transcribed, with oppBCDF forming an operon. Sizeable intergenic regions separate the $B$. burgdorferi oppA genes (oppAI-II, $119 \mathrm{bp}$; oppAII-III, $139 \mathrm{bp}$; oppAIII$o p p B, 355 \mathrm{bp}$ ), whereas only a few bases separate the

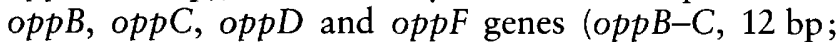
$o p p C-D, 11$ bp; oppD-F, 3 bp; see gene diagram in Fig. 2). An alignment of approximately 100 nucleotides upstream of the initiation codon for each $o p p A$ gene indicated very little conservation of sequence in the potential promoter regions (not shown). Computer analysis of these regions using the program MACTARG SEARCH did not identify any sequence that had greater than $60 \%$ identity with that of a consensus sigma 70 promoter from E. coli, in contrast to several other borrelial genes, which have sigma 70-like promoters (Bergstrom et al., 1989; Reindl et al., 1993; Simpson et al., 1994; Stevenson et al., 1996; Wallich et al., 1993; Zhang et al., 1997). The regions between the chromosomal oppA genes contain short, imperfect inverted repeats, but no sequences resembling rho-independent terminators.

Since the $B$. burgdorferi oppA genes share significant sequence identity, probes encompassing them crosshybridize (Fig. 1 and data not shown), so developing gene-specific probes was a necessary prelude to undertaking studies of $o p p A$ gene expression. Within the most divergent portion of each gene (encoding amino acid residues $230-300$, Fig. 3), the oppA genes share less than $60 \%$ nucleotide identity with each other. Probes from these regions were shown to be specific for the oppA gene from which they were derived by hybridization to plasmid DNA containing cloned segments from individual oppA genes (Fig. 4a). The probes did not crossreact with other $o p p A$ genes, even when the blots were overexposed.

Expression of B. burgdorferi opp genes in mid-exponential-phase cultures was monitored by Northern blot analysis of total RNA with probes for $o p p A \mathrm{I}-\mathrm{V}, o p p B C$ and $o p p D$. Three transcripts were detected when a probe specific for $o p p A I I$ was used (Fig. 4b). The sizes of these transcripts correspond to those predicted for messages that encompass one $(1.8 \mathrm{~kb})$, two $(4.1 \mathrm{~kb})$ or three $(6.2 \mathrm{~kb})$ ) oppA genes (Fig. $4 \mathrm{~b}$, oppAII, arrows 1,2 and 3 , respectively). Similar results were obtained using the $о p p A \mathrm{I}$ and $o p p A I I I$ probes (not shown); the large $6.2 \mathrm{~kb}$ transcript was the least abundant, but detectable with all three probes. These results suggest that transcription initiates at each $o p p A$ gene, but can also proceed through the intergenic regions and downstream $o p p A$ genes at the chromosomal locus. Alternatively, processing of a single large transcript initiating upstream of $o p p A \mathrm{I}$ could result in a similar banding pattern. Only a $1.8 \mathrm{~kb}$ transcript was detected for each of the plasmidlocated $o p p A I V$ and $o p p A V$ genes (Fig. $4 \mathrm{~b}$ ). As a preliminary step toward assessing the functional significance of the five B. burgdorferi OppA proteins, we inactivated the oppAIV gene by allelic exchange (described in Methods). No oppAIV transcript was detected in the oppAIV mutant, although it did contain transcripts of the three chromosomal oppA genes (Fig. 4b).

Different preparations of RNA yielded varying proportions of mono-, bi- and tri-cistronic transcripts from the chromosomal oppA genes, but their relative abundances did not correlate with known culture variables. Transcripts of the three chromosomal oppA genes and of oppAIV (on cp26) were not more abundant in $B$. burgdorferi cultures that were grown at $23^{\circ} \mathrm{C}$ and then shifted to $35^{\circ} \mathrm{C}$ (data not shown), but the transcript from oppAV (on $1 \mathrm{p} 54$ ) was consistently increased in cultures shifted to $35^{\circ} \mathrm{C}$ (Fig. $4 \mathrm{~b}$, oppAV). The oppAV transcript was also present at a much lower level than those of the chromosomal oppA genes or oppAIV, even after induction at $35^{\circ} \mathrm{C}$; the oppAV blot was exposed for approximately $6 \mathrm{~d}$, compared to $6 \mathrm{~h}$ exposures for the oppAII and oppAIV blots (Fig. 4b). Hybridization of the same RNA preparations with a probe to the constitutively expressed flagellin gene indicated comparable amounts of RNA in all samples (Fig. 4c) and the quality of each RNA was demonstrated by the integrity of the rRNA bands in ethidium bromide-stained gels (Fig. $4 \mathrm{~b}$ and data not shown).

No distinct transcripts were detected with probes from the $o p p B, o p p C$ and $o p p D$ genes; instead, a broad band was visible after relatively long exposures with the $o p p D$ probe $(45 \mathrm{~h}$, Fig. $4 \mathrm{~b})$ or a larger probe spanning $o p p B$ and $o p p C$ (not shown). No oppA or oppD probe detected a transcript that was long enough to extend from $o p p A \mathrm{I}$ through $o p p D$.

\section{Synthesis of OppAIV}

To begin studies of OppA protein levels and location, OppAIV was synthesized as a recombinant fusion with maltose-binding protein in E. coli and a rabbit polyclonal serum was raised against the purified recombinant protein. Only faint reactivity was evident when an immunoblot containing a protein lysate from the 
(a)
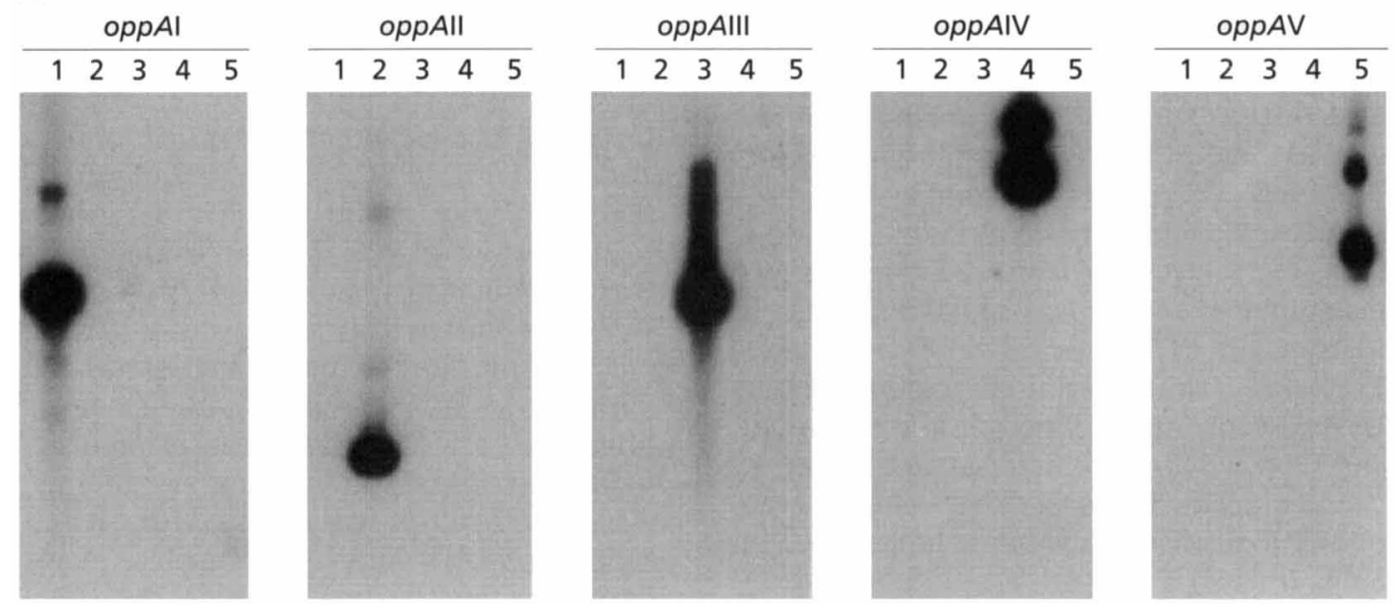

(b)
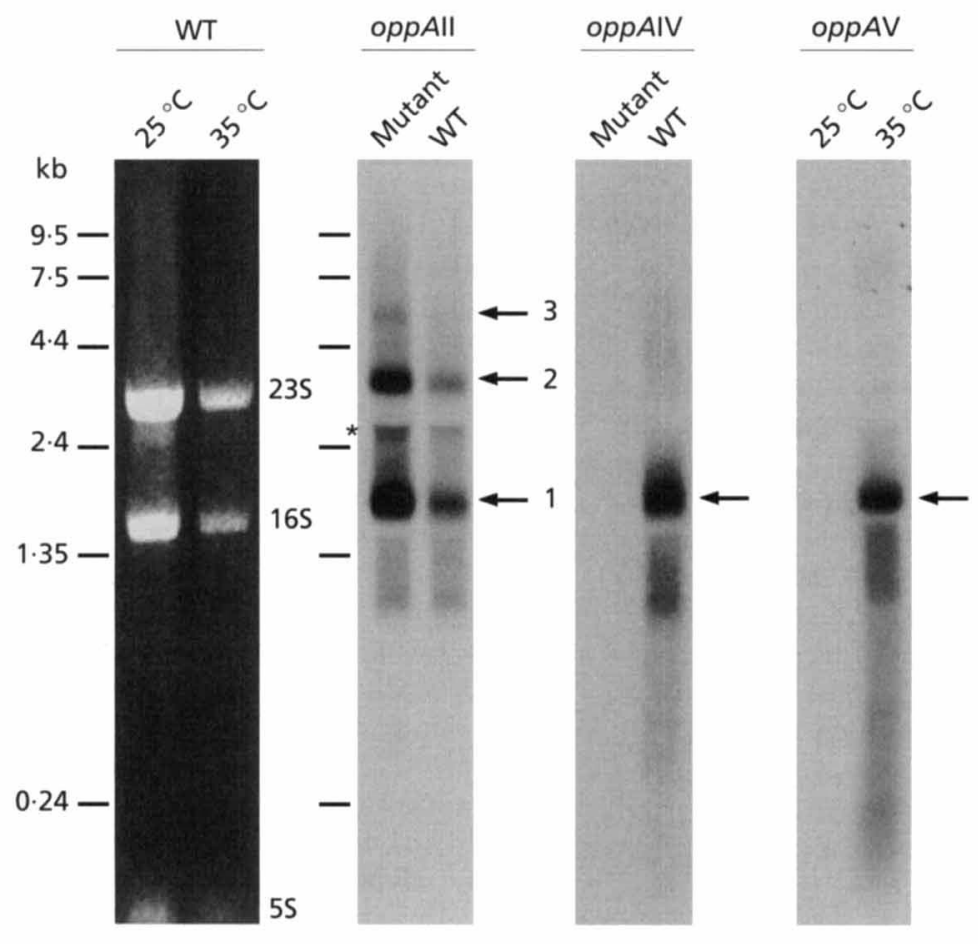

oppD

(c)
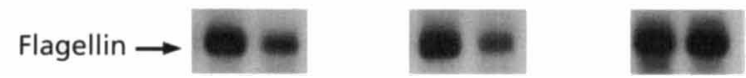

Fig. 4. (a) High-stringency Southern blot analysis of cloned oppA genes with specific probes. Recombinant plasmids containing individual $B$. burgdorferi oppA genes were digested with EcoRI (except oppAIV), separated by agarose gel electrophoresis, blotted and hybridized at $55^{\circ} \mathrm{C}$ with oppA gene-specific probes, as indicated at the top of each panel. Plasmid DNA was as follows: lane 1, oppAl; lane 2, oppAll; lane 3, oppAlll; lane 4, oppAIV; lane 5, oppAV. (b) Analysis of opp transcripts. Left panel, ethidium-bromide-stained gel of RNA from $B$. burgdorferi indicating the mobilities of 55 , 165 and $23 S$ rRNAs relative to the hybridizing bands on the blots. Remaining panels, Northern blots were hybridized with probes as indicated above each panel. The oppAll and oppAIV probes were hybridized with RNA from $B$. burgdorferi oppAIV mutant (mutant) and wild-type (WT) bacteria. Arrows indicate the mobilities of mono- (1), bi- (2) and tri-cistronic (3) oppA transcripts hybridizing with the oppAll probe. We assume that the hybridizing band $\left({ }^{*}\right)$ below the 235 rRNA band results from smaller RNA species being pushed in front of the rRNA and is not a discrete oppA transcript. The oppAV probe was hybridized with RNA from wild-type $B$. burgdorferi grown at $23^{\circ} \mathrm{C}$ or shifted to $35^{\circ} \mathrm{C}$. The oppD probe was hybridized with RNA from wild-type $B$. burgdorferi grown at $35^{\circ} \mathrm{C}$. Mobilities of size standards $(0.24-9.5 \mathrm{~kb}$ RNA ladder, Life Technologies) are indicated on the left of the ethidium-stained gel and first Northern blot panel. (c) The blots described above were allowed to decay and hybridized with a flagellin probe to assure equivalent loading of RNA in each lane. 
(a)

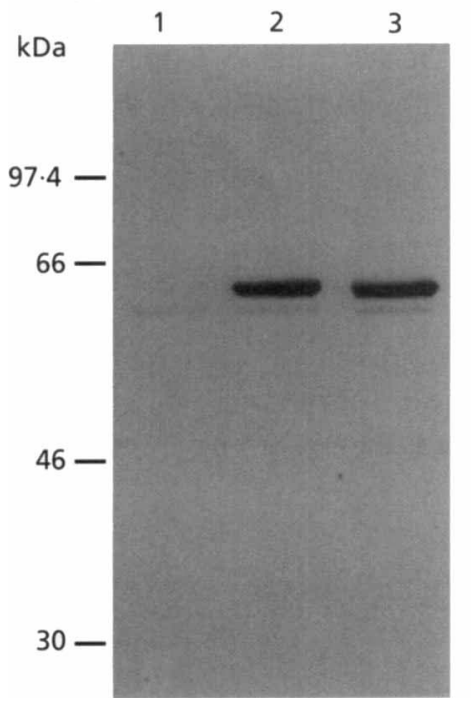

(b)

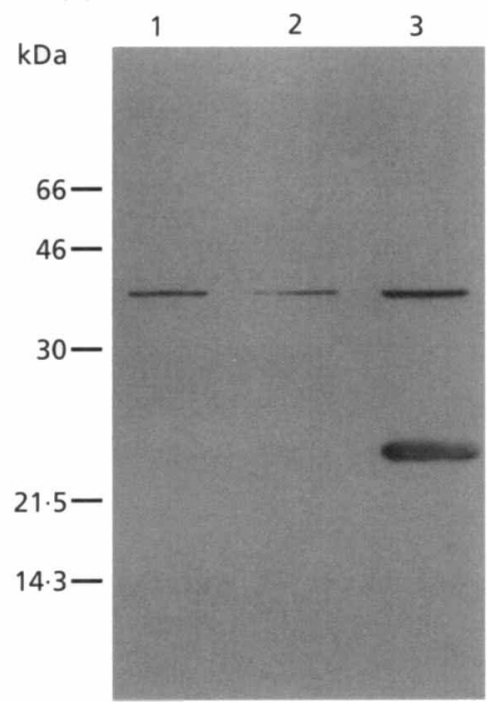

Fig. 5. Immunoblot analysis of wild-type and oppAIV mutant $B$. burgdorferi. Lysates of oppAIV mutant B31-82 (lane 1) and wildtype $B$. burgdorferi grown at $23^{\circ} \mathrm{C}$ (lane 2) or shifted to $35^{\circ} \mathrm{C}$ (lane 3) were separated by SDS-PAGE and identical blots were incubated with (a) OppA- or (b) OspCspecific sera. Mobilities of protein size standards (kDa) are indicated. The $35 \mathrm{kDa}$ protein recognized by the anti-OspC antiserum in all samples has been noticed previously and is unrelated to OspC (Norris et al., 1992; Schwan et al., 1993; Tilly et al., 1997). (a)

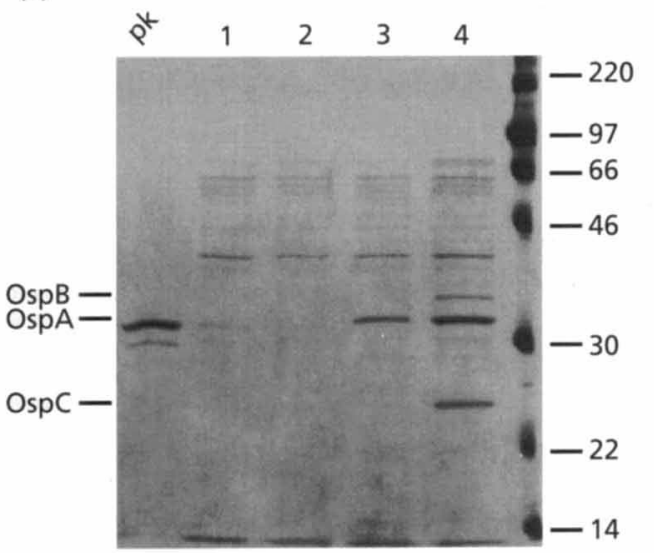

(b)

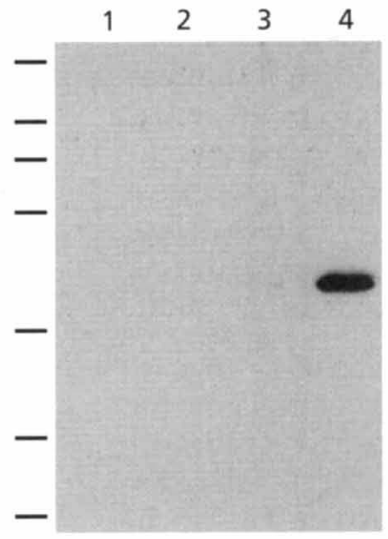

(c)

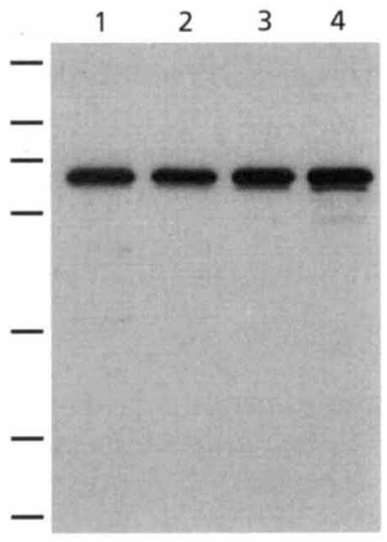

Fig. 6. Proteinase $K$ sensitivity of OppAIV on intact $B$. burgdorferi. Live, unfixed bacteria were treated with different concentrations of Proteinase K: $1 \mathrm{mg} \mathrm{ml}^{-1}$ (lane 1), $0.2 \mathrm{mg} \mathrm{ml}^{-1}$ (lane 2), $0.04 \mathrm{mg} \mathrm{ml}^{-1}$ (lane 3), and $0.0 \mathrm{mg} \mathrm{ml}^{-1}$ (lane 4). Lysates of treated bacteria were separated by SDS-PAGE and either stained with Coomassie brilliant blue (a), or analysed by immunoblot with OspB (b) and OppAIV (c) antisera. The mobility of proteinase K (pk) is indicated on the Coomassiestained gel. The mobilities of protein size standards $(\mathrm{kDa})$ are indicated.

oppAIV mutant was probed (Fig. 5a, lane 1), indicating that the majority of the protein recognized by this antiserum in wild-type $B$. burgdorferi lysates (Fig. 5a, lanes 2 and 3 ) is the oppAIV gene product. The other four B. burgdorferi OppA proteins were also synthesized as recombinant proteins in E. coli and bacterial lysates were tested by immunoblotting; the OppAIV antiserum cross-reacted only very weakly with OppAI, II, III and V (data not shown).

Lysates of wild-type B. burgdorferi grown at $23{ }^{\circ} \mathrm{C}$ and then shifted to $35^{\circ} \mathrm{C}$ were probed by immunoblotting to determine if there were an increase in OppAIV, as had been found for OspC (Schwan et al., 1995). Bacteria grown at both temperatures contained similar amounts of OppAIV (Fig. 5a, compare lanes 2 and 3), consistent with oppAIV transcript levels, whereas OspC was only detected in the culture shifted to $35^{\circ} \mathrm{C}$ (Fig. 5 b, compare lanes 2 and 3 ).

\section{Surface inaccessibility of OppA}

To determine if the borrelial OppA proteins were surface-exposed, intact borreliae were treated with varying amounts of proteinase $\mathrm{K}$ and bacterial lysates were immunoblotted with OppAIV and OspB polyclonal sera (Fig. 6). Whereas only a slight diminution in OppAIV was seen at even the highest concentration of proteinase $\mathrm{K}$ (1 $\mathrm{mg} \mathrm{ml}^{-1}$; lane 1, Fig. 6), OspB, a surfaceexposed lipoprotein, was completely degraded at the lowest concentration of proteinase $\mathrm{K} \quad\left(0.04 \mathrm{mg} \mathrm{ml}^{-1}\right.$; lane 3, Fig. 6), relative to the control lysate without 
proteinase $\mathrm{K}$ treatment (lane 4, Fig. 6). Analysis of the same bacterial lysates by Coomassie blue stain indicated that two other surface-exposed lipoproteins, OspA and OspC, were also degraded by proteinase $\mathrm{K}$ treatment, although OspA was somewhat resistant at the lowest concentration $\left(0.04 \mathrm{mg} \mathrm{ml}^{-1}\right.$; lane 3 , Fig. 6). We conclude that, in contrast with several borrelial outersurface lipoproteins, OppAIV of intact organisms resists digestion by proteinase $\mathrm{K}$ and may have a periplasmic location.

\section{DISCUSSION}

\section{Multiple substrate-binding components in B. burgdorferi}

Typically, the genes encoding all the components of oligopeptide permease are present at a single chromosomal locus. An interesting feature of the putative $B$. burgdorferi transporter is the presence of multiple substrate-binding components (OppA homologues), encoded by both plasmid and chromosomal loci. Some other bacteria have additional substrate-binding components encoded on plasmids or elsewhere on the chromosome (Alloing et al., 1994; Jenkinson et al., 1996; Leonard et al., 1996; Ruhfel et al., 1993; Tanimoto et al., 1993). It is intriguing to consider the possibility that the B. burgdorferi plasmid-encoded OppA homologues recognize peptide signals that induce an adaptive response, since these plasmids also carry outer-surface protein genes that are differentially expressed during transmission from ticks to mammals (de Silva et al., 1996; Schwan et al., 1995).

In addition to multiple peptide-binding components for a single oligopeptide permease, separate transport systems can exist for peptides of different sizes or characteristics (Hiles et al., 1987b; Koide \& Hoch, 1994). Components of the putative B. burgdorferi peptide permease are most similar to oligopeptide (Opp) transport components. However, substrate specificities cannot be assigned on the basis of sequence similarity alone, and biochemical and genetic studies are necessary before the physiological role and peptide specificity of this system in $B$. burgdorferi can be determined. Borreliae grow in the laboratory only in a complex, undefined medium, hence complicating in vitro studies to directly characterize peptide transport in these bacteria. Expression of oppAIV in a Bacillus subtilis $o p p A$ mutant did not restore general peptide transport, as assayed by resistance to the toxic peptide bialophos and failure of a methionine auxotroph to grow in medium in which peptides were the sole source of amino acids (unpublished data). These data suggest that OppAIV does not bind peptides non-specifically, but are inconclusive due to the nature of negative complementation results in a heterologous system.

\section{OppAIV not essential for in vitro growth}

As an initial step toward understanding the role of oligopeptide permease in the transmission and adap- tation of $B$. burgdorferi between the arthropod and mammalian environments, we have inactivated oppAIV, the cp26-encoded gene. We suspect that the oppAIV product could play an important role in sensing environmental signals in the form of peptides. oppAIV was inactivated in a non-infectious, laboratory-adapted $B$. burgdorferi, with the intention of subsequently moving this mutation into an infectious isolate. However, we have not succeeded in transforming low-passage infectious $B$. burgdorferi and thus have been unable to directly test the effect of this mutation in the infectious cycle. Clearly, B. burgdorferi does not require OppAIV for growth in culture medium.

\section{Homologue of OppAll not essential for in vivo infectivity}

Das et al. (1996) previously described a $30 \mathrm{kDa}$ protein (P30) from B. burgdorferi isolate N40 that is homologous to periplasmic substrate-binding proteins of Gram-negative bacteria. Extensive sequence similarity strongly suggests that $p 30$ and $o p p A I I$ are alleles of the same gene from two different $B$. burgdorferi isolates. The disparity in size between P30 and OppAII $(30 \mathrm{kDa}$ versus $58 \mathrm{kDa}$, respectively) derives from a base deletion in the $p 30$ gene, which results in a frame shift and premature stop codon. $\mathrm{P} 30$ probably is not a functional substrate-binding protein because much of the peptidebinding pocket (Tame et al., 1994) is missing. Despite this mutation, B. burgdorferi N40 maintains a mammal-tick infectivity cycle (Fikrig et al., 1992). These data suggest that $p 30$ represents a naturally occurring oppAII mutant and that there may be functional redundancy among the five $B$. burgdorferi OppA proteins such that they are not all essential in vivo.

\section{Cellular location of substrate-binding components}

The substrate-binding components of high-affinity transport systems are located in the periplasm of Gramnegative bacteria. In Gram-positive bacteria, which lack an outer membrane, these 'periplasmic binding proteins' such as OppA, are surface-exposed lipoproteins that are anchored to the cytoplasmic membrane by an amino-terminal lipid moiety (Gilson et al., 1988; Perego et al., 1991). The deduced amino acid sequences of the $B$. burgdorferi OppA homologues suggest that they are membrane-bound lipoproteins, yet the surface-inaccessibility of one of these proteins (OppAIV) is consistent with a periplasmic location. The borrelial substrate-binding proteins may be periplasmic, but associated with the cytoplasmic membrane by a lipid moiety, thus combining features of both Gram-positive and Gram-negative bacteria. In another spirochaete, Treponema pallidum, a protein with homology to the substrate-binding components of $\mathrm{ABC}$ transporters is primarily associated with the cytoplasmic membrane (Akins et al., 1997). 


\section{Concluding remarks}

In conclusion, we have characterized a chromosomal locus and two plasmid loci in B. burgdorferi that encode homologues of oligopeptide permease components. To determine the function of this transporter we are pursuing biochemical and genetic studies to investigate the peptide-binding characteristics and biological roles of the five different substrate-binding components. We speculate that $B$. burgdorferi might utilize peptide pheromones to elicit a concerted adaptive response to changing environmental conditions, such as those that the bacteria encounter as they cycle between ticks and mammals.

\section{ACKNOWLEDGEMENTS}

We are grateful to $S$. Samuels for his pioneering work in developing transformation and a selectable marker in borreliae, and for providing primers used in amplifying $g y r B$. We thank J. Leong for bringing to our attention the sequence of an oppA homologue from B. coriaceae, S. Casjens for assistance in mapping the $o p p$ loci, T. Schwan for providing the OspB and OspC antisera, S. Porcella for advice on RNA extraction and automated sequencing, J. Fuhrman for assistance with the complementation studies in B. subtilis, and J. Hoch for providing bialophos. We thank S. Smaus for assistance in manuscript preparation, G. Hettrick and R. Evans for artwork and photography, J. Hinnebusch, T. Schwan and S. Porcella for helpful comments on the manuscript, and J. Tame and A. Grossman for discussion.

\section{REFERENCES}

Akins, D. R., Robinson, E., Shevchenko, D., Elkins, C., Cox, D. L. \& Radolf, J. D. (1997). Tromp1, a putative rare outer membrane protein, is anchored by an uncleaved signal sequence to the Treponema pallidum cytoplasmic membrane. J Bacteriol 179, 5076-5086.

Alloing, G., de Philip, P. \& Claverys, J.-P. (1994). Three highly homologous membrane-bound lipoproteins participate in oligopeptide transport by the Ami system of the Gram-positive Streptococcus pneumoniae. J Mol Biol 241, 44-58.

Altschul, S. F., Gish, W., Miller, W., Myers, E. W. \& Lipman, D. J. (1990). Basic local alignment search tool. J Mol Biol 215, 403-410.

Arraj, J. A. \& Marinus, M. G. (1983). Phenotypic reversal in dam mutants of Escherichia coli K-12 by a recombinant plasmid containing the dam ${ }^{+}$gene. $J$ Bacteriol 153, 562-565.

Barbour, A. G. (1984). Isolation and cultivation of Lyme disease spirochetes. Yale J Biol Med 57, 521-525.

Barbour, A. G., Tessier, S. L. \& Hayes, S. F. (1984). Variation in a major surface protein of Lyme disease spirochetes. Infect Immun 45, 94-100.

Bergstrom, S., Bundoc, V. G. \& Barbour, A. G. (1989). Molecular analysis of linear plasmid-encoded major surface proteins, OspA and $\mathrm{OspB}$, of the Lyme disease spirochete Borrelia burgdorferi. Mol Microbiol 3, 479-486.

Burgdorfer, W., Barbour, A. G., Hayes, S. F., Benach, J. L., Grunwaldt, E. \& Davis, J. P. (1982). Lyme disease - a tick-borne spirochetosis? Science 216, 1317-1319.

Clewell, D. B. (1993). Bacterial sex pheromone-induced plasmid transfer. Cell 73, 9-12.

Das, S., Shraga, D., Gannon, C. \& 7 other authors (1996).
Characterization of a $30-\mathrm{kDa}$ Borrelia burgdorferi substratebinding protein homologue. Res Microbiol 147, 739-751.

Dassa, E. \& Hofnung, M. (1985). Sequence of gene malG in E. coli $\mathrm{K} 12$ : homologies between integral membrane components from binding protein-dependent transport systems. EMBO $J \mathbf{4}$, 2287-2293.

Fikrig, E., Telford, S. R., III, Barthold, S. W., Kantor, F. S., Spielman, A. \& Flavell, R. A. (1992). Elimination of Borrelia burgdorferi from vector ticks feeding on OspA-immunized mice. Proc Natl Acad Sci USA 89, 5418-5421.

Gilson, E., Alloing, G., Schmidt, T., Claverys, J.-P., Dudler, R. \& Hofnung, M. (1988). Evidence for high affinity binding-protein dependent transport systems in Gram-positive bacteria and in Mycoplasma. EMBO J 7, 3971-3974.

Goodell, E. W. \& Higgins, C. F. (1987). Uptake of cell wall peptides by Salmonella typhimurium and Escherichia coli.J Bacteriol 169, 3861-3865.

Higgins, C. F. (1992). ABC transporters: from microorganisms to man. Annu Rev Cell Biol 8, 67-113.

Higgins, C. F. \& 10 other authors (1986). A family of related ATPbinding subunits coupled to many distinct biological processes in bacteria. Nature 323, 448-450.

Hiles, I. D., Gallagher, M. P., Jamieson, D. J. \& Higgins, C. F. (1987a). Molecular characterization of the oligopeptide permease of Salmonella typhimurium. J Mol Biol 195, 125-142.

Hiles, I. D., Powell, L. M. \& Higgins, C. F. (1987b). Peptide transport in Salmonella typhimurium: molecular cloning and characterization of the oligopeptide permease genes. Mol Gen Genet 206, 101-109.

Hyde, S. C., Emsley, P., Hartshorn, M. J. \& 7 other authors (1990). Structural model of ATP-binding proteins associated with cystic fibrosis, multidrug resistance and bacterial transport. Nature 346, 362-365.

Jenkinson, H. F., Baker, R. A. \& Tannock, G. W. (1996). A bindinglipoprotein-dependent oligopeptide transport system in Streptococcus gordonii essential for uptake of hexa- and heptapeptides. J Bacteriol 178, 68-77.

King, G. J. \& Swanson, J. (1978). Studies on gonococcus infection. $\mathrm{XV}$. Identification of surface proteins of Neisseria gonorrhoeae correlated with leukocyte association. Infect Immun 21, 575-584.

Kitten, T. \& Barbour, A. G. (1992). The relapsing fever agent Borrelia hermsii has multiple copies of its chromosome and linear plasmids. Genetics 132, 311-324.

Koide, A. \& Hoch, J. A. (1994). Identification of a second oligopeptide transport system in Bacillus subtilis and determination of its role in sporulation. Mol Microbiol 13, 417-426.

Lane, R. S., Piesman, J. \& Burgdorfer, W. (1991). Lyme borreliosis: relation of its causative agent to its vectors and hosts in North America and Europe. Annu Rev Entomol 36, 587-609.

Leonard, B. A. B., Podbielski, A., Hedberg, P. J. \& Dunny, G. M. (1996). Enterococcus faecalis pheromone binding protein, $\operatorname{PrgZ\text {,}}$ recruits a chromosomal oligopeptide permease system to import sex pheromone cCF10 for induction of conjugation. Proc Natl Acad Sci USA 93, 260-264.

Margolis, N., Hogan, D., Tilly, K. \& Rosa, P. A. (1994). Plasmid location of Borrelia purine biosynthesis gene homologs. J Bacteriol 176, 6427-6432.

Mimura, C. S., Holbrook, S. R. \& Ames, G. F.-L. (1991). Structural model of the nucleotide-binding conserved component of periplasmic permeases. Proc Natl Acad Sci USA 88, 84-88.

Norris, S. J., Carter, C. J., Howell, J. K. \& Barbour, A. G. (1992). 
Low-passage-associated proteins of Borrelia burgdorferi B31: characterization and molecular cloning of OspD, a surfaceexposed, plasmid-encoded lipoprotein. Infect Immun 60, 46624672.

Payne, J.W. \& Gilvarg, C. (1968). Size restriction on peptide utilization in Escherichia coli. J Biol Chem 243, 6291-6299.

Pearce, S. R., Mimmack, M. L., Gallagher, M. P., Gileadi, U., Hyde, S. C. \& Higgins, C. F. (1992). Membrane topology of the integral membrane components, $\mathrm{OppB}$ and $\mathrm{OppC}$, of the oligopeptide permease of Salmonella typhimurium. Mol Microbiol 6, 47-57.

Perego, M., Higgins, C. F., Pearce, S. R., Gallagher, M. P. \& Hoch, J. A. (1991). The oligopeptide transport system of Bacillus subtilis plays a role in the initiation of sporulation. Mol Microbiol 5, 173-185.

Reindl, M., RedI, B. \& Stoffler, G. (1993). Isolation and analysis of a linear plasmid-located gene of Borrelia burgdorferi B29 encoding a $27 \mathrm{kDa}$ surface lipoprotein (P27) and its overexpression in Escherichia coli. Mol Microbiol 8, 1115-1124.

Rosa, P. A. \& Schwan, T. G. (1989). A specific and sensitive assay for the Lyme disease spirochete Borrelia burgdorferi using the polymerase chain reaction. J Infect Dis 160, 1018-1029.

Rosa, P. A., Schwan, T. \& Hogan, D. (1992). Recombination between genes encoding major outer surface proteins $A$ and $B$ of Borrelia burgdorferi. Mol Microbiol 6, 3031-3040.

Rosa, P., Samuels, D. S., Hogan, D., Stevenson, B., Casjens, S. \& Tilly, K. (1996). Directed insertion of a selectable marker into a circular plasmid of Borrelia burgdorferi. J Bacteriol 178, 59465953.

Rudner, D. Z., LeDeaux, J. R., Ireton, K. \& Grossman, A. D. (1991). The spoOK locus of Bacillus subtilis is homologous to the oligopeptide permease locus and is required for sporulation and competence. J Bacteriol 173, 1388-1398.

Ruhfel, R. E., Manias, D. A. \& Dunny, G. M. (1993). Cloning and characterization of a region of the Enterococcus faecalis conjugative plasmid, pCF10, encoding a sex pheromone-binding function. J Bacteriol 175, 5253-5259.

Sambrook, J., Fritsch, E. F. \& Maniatis, T. (1989). Molecular Cloning: a Laboratory Manual, 2nd edn. Cold Spring Harbor, NY : Cold Spring Harbor Laboratory.

Samuels, D. S., Mach, K. E. \& Garon, C. F. (1994). Genetic transformation of the Lyme disease agent Borrelia burgdorferi with coumarin-resistant gyrB. J Bacteriol 176, 6045-6049.

Schwan, T. G., Schrumpf, M. E., Karstens, R. H., Clover, J. R., Wong, J., Daugherty, M., Struthers, M. \& Rosa, P. A. (1993). Distribution and molecular analysis of Lyme disease spirochetes, Borrelia burgdorferi, isolated from ticks throughout California. J Clin Microbiol 31, 3096-3108.

Schwan, T. G., Piesman, J., Golde, W. T., Dolan, M. C. \& Rosa, P. A. (1995). Induction of an outer surface protein on Borrelia burgdorferi during tick feeding. Proc Natl Acad Sci USA 92, 2909-2913. de Silva, A. M., Telford, S. R., III, Brunet, L. R., Barthold, S. W. \& Fikrig, E. (1996). Borrelia burgdorferi OspA is an arthropodspecific transmission-blocking Lyme disease vaccine. J Exp Med 183, 271-275.

Simpson, W. J., Cieplak, W., Schrumpf, M. E., Barbour, A. G. \& Schwan, T. G. (1994). Nucleotide sequence and analysis of the gene in Borrelia burgdorferi encoding the immunogenic P39 antigen. FEMS Microbiol Lett 119, 381-388.

Southern, E. M. (1975). Detection of specific sequences among DNA fragments separated by gel electrophoresis. J Mol Biol 98, 503-517.

Stevenson, B., Tilly, K. \& Rosa, P. A. (1996). A family of genes located on four separate 32-kilobase circular plasmids in Borrelia burgdorferi B31. J Bacteriol 178, 3508-3516.

Tam, R. \& Saier, M. H., Jr (1993). Structural, functional, and evolutionary relationships among extracellular solute-binding receptors of bacteria. Microbiol Rev 57, 320-346.

Tame, J. R. H., Murshudov, G. N., Dodson, E. J., Neil, T. K., Dodson, G. G., Higgins, C. F. \& Wilkinson, A. J. (1994). The structural basis of sequence-independent peptide binding of OppA protein. Science 264, 1578-1581.

Tanimoto, K., An, F. Y. \& Clewell, D. B. (1993). Characterization of the traC determinant of the Enterococcus faecalis hemolysinbacteriocin plasmid pAD1: binding of sex pheromone. J Bacteriol $175,5260-5264$.

Tilly, K., Casjens, S., Stevenson, B., Bono, J. L., Samuels, D. S., Hogan, D. \& Rosa, P. (1997). The Borrelia burgdorferi circular plasmid cp 26: conservation of plasmid structure and targeted inactivation of the ospC gene. Mol Microbiol 25, 361-373.

Walker, J. E., Saraste, M., Runswick, M. J. \& Gay, N. J. (1982). Distantly related sequences in the $\alpha$ - and $\beta$-subunits of ATP synthase, myosin, kinases and other ATP-requiring enzymes and a common nucleotide binding fold. EMBO J 1, 945-951.

Wallich, R., Simon, M. M., Hofmann, H., Moter, S. E., Schaible, U. E. \& Kramer, M. D. (1993). Molecular and immunological characterization of a novel polymorphic lipoprotein of Borrelia burgdorferi. Infect Immun 61, 4158-4166.

Wu, H. C. \& Tokunaga, M. (1986). Biogenesis of lipoproteins in bacteria. Curr Top Microbiol Immunol 125, 127-157.

Zhang, J.-R., Hardham, J. M., Barbour, A. G. \& Norris, S. J. (1997). Antigenic variation in Lyme disease borreliae by promiscuous recombination of VMP-like sequence cassettes. Cell 89, 1-20.

Zingg, B. C. \& LeFebvre, R. B. (1994). Polymerase chain reaction for detection of Borrelia coriaceae, putative agent of epizootic bovine abortion. Am J Vet Res 55, 1509-1515.

Received 3 September 1997; revised 13 November 1997; accepted 28 November 1997. 